\title{
¿ENFERMEDADES DE MINORÍAS?
}

\author{
Favio Rivas Muñoz*
}

Resumen: Las recientes amenazas de pandemias han puesto al descubierto que, por más difíciles y aún desconocidos, los problemas que pongan en riesgo la salud en el ámbito internacional pueden ser controlados rápida y efectivamente, es decir, el poco desarrollo técnico y científico, de recursos humanos o de dinero no constituye un obstáculo hacia una respuesta adecuada. En último término, la clave del éxito en esta materia no está en la técnica o en la ciencia, y la razón fundamental para el desigual panorama de salud en la aldea global quizás esté en la exclusión de poblaciones consideradas simplemente innecesarias desde la óptica de los mercaderes y sus leyes, o también señaladas como culpables de sus males por efecto de su propia cultura. El presente ensayo se ocupa de mostrar que la salud pública es un asunto de comercio más que de ciencia, de política o de ética.

Palabras clave: enfermedad, minoría, globalización, mercado, cultura

\section{¿DISEASES OF MINORITIES?}

Abstract: Pandemic recent threats have uncover that, even being more difficult and unknown, the problems that risk health at international level can be controlled quickly and effectively, that is, having little technical and scientific development, human resources or money are not an obstacle to give an appropriate response. Lastly, the key of success in this matter is not found in techniques or science and the basic reason for global unequal health scene perhaps is found in the exclusion of populations considered simply unnecessary from the market and its regulations perspective, or also pointed out as guilty of their maladies because of their own culture. The present study tries to show that public health is a matter of business more than science, politics or ethics.

Key words: disease, minority, globalization, market, culture

\section{ENFERMIDADES DE MINORIAS?}

Resumo: As recentes ameaças de pandemias têm colocado a descoberto que por mais difíceis e ainda desconhecidos, os problemas que póem em risco a saúde no âmbito internacional podem ser controlados rápida e efetivamente, ou seja, o pouco desenvolvimento técnico e científico de recursos humanos ou dinheiro não constitui um obstáculo para uma resposta adequada. Em último termo, a chave do êxito nesta matéria não está na técnica ou na ciência e a razão fundamental para o desigual panorama de saúde na aldeia global quiçá esteja na exclusão de populaçôes consideradas simplesmente desnecessárias pela ótica dos mercadores e de suas leis, ou também assinaladas como culpadas de seus males por efeito de sua própria cultura. O presente ensaio se ocupa em mostrar que a saúde pública é um assunto mais de comércio do que de ciência, política ou de ética.

Palavras-chave: enfermidade, minoria, globalização, mercado, cultura

\footnotetext{
Profesor Asociado, Departamento de Salud Pública, Facultad de Medicina, Universidad Nacional de Colombia, Colombia
} Correspondencia: farivasm@unal.edu.co 


\section{Introducción}

Hace un poco más de 25 años se detectó el primer caso de SIDA en Los Angeles (USA). La epidemia se tornó pandemia y hoy los cinco continentes registran casos a la Organización Mundial de la Salud (OMS) ${ }^{1}$. En aquella época, Ronald Reagan se estrenaba como presidente y los dineros requeridos para investigar las causas de esa epidemia, que afectaba inicialmente a homosexuales y bisexuales de sexo masculino, no se obtuvieron sino hasta cuando la desgracia afectó a "personas de bien", como famosos actores de cine, senadores o miembros de ciertas familias. Aparte de los hombres homosexuales y bisexuales, una de las primeras comunidades afectadas fue la de residentes haitianos en el estado de La Florida. Ambos grupos poblacionales no eran otra cosa que parias, marginados, minorías que a nadie importaban. El SIDA mostró crudamente esa realidad al interior del más avanzado de los países del Occidente desarrollado. La realidad era que había enfermos que importaban y otros que no, y si eso era así había enfermedades que importaban y otras que no, según el tipo de personas o poblaciones a las que afectaban.

Como ocurrió con el VIH/SIDA, la globalización ha ratificado que en el mundo las enfermedades sí importan, claro está, siempre y cuando afecten "personas de bien" o pongan en riesgo a quienes habiten los países más avanzados o las comunidades acomodadas de los países no desarrollados. Para estas enfermedades se asignan recursos, para otras simplemente no los hay. El avance del SARS (Síndrome Agudo Respiratorio Severo, por sus siglas en inglés) fue interrumpido eficaz y prontamente a pesar de su rápida diseminación por tres países en dos continentes. En menos de dos semanas ya había salido de Hong Kong hacia Canadá y tanto en estos como prácticamente en todos los países del orbe se tomaron las medidas que impidieron su diseminación global. La demostración fue contundente: no importa si una epidemia es causada por un agente desconocido, todo lo necesario se puede suministrar a científicos y gobiernos en tiempo récord si pone en riesgo el turismo o los negocios internacionales. Se cuantificaron las pérdidas económicas con tanta o más premura que las humanas. Es claro, la globalización opera, se persigue que la economía esté bien bajo el

1 La Organización Mundial de la Salud, junto con otros organismos internacionales de carácter no gubernamental, se han reunido en ONUSIDA, el Programa de Naciones Unidas para la Prevención y Control del VIH/SIDA en el mundo. supuesto de que si ella lo está todos lo estaremos. Lo definitivamente claro es que la economía no puede ni debe enfermarse y de su salud debemos ocuparnos todos los seres humanos, independientemente de donde habitemos en la aldea.

En el pasado hubo respuestas para enfermedades que pusieron en peligro los negocios. Eso mismo sigue ocurriendo en el presente y nada impide pensar que vaya a dejar de ocurrir en el futuro. A pesar de ello, cualquier respuesta ha brillado por su ausencia en relación con la malaria, que lleva más de 30 años causando la muerte de hasta tres millones de personas cada año, la gran mayoría en África y Asia². A pesar de la magnitud que alcanzan las cifras, sigue en los mismos lugares y afectando las mismas poblaciones, aquellas que para la economía del mercado nada importan, pues simplemente nada compran, ni alimentos, ni autos, ni medicamentos, y tampoco venden. Acerca del parásito y el mosquito que la transmite se conoce todo lo necesario para reducir de manera efectiva la transmisión y puede decirse que prácticamente no se requiere más investigación al respecto, sólo tomar las medidas que se sabe funcionan. Sin embargo, los gobiernos de los países afectados no toman las decisiones y nada los obliga a hacerlo.

Claro está, en materia de comercio operan códigos internacionales y leyes que obligan y presionan gobiernos. Tales presiones son económicas y por esa vía es probable algún impacto beneficioso en salud pública, un efecto colateral que permita cierto mejoramiento en ese terreno. Un ejemplo ilustra bastante bien lo que se ha dicho hasta aquí: la situación de salud pública de algunos puertos colombianos hace algo más de 100 años debió haber mejorado luego de la venida de la Oficina Sanitaria Internacional, que finalmente se llamó Organización Panamericana de la Salud, agencia en cuyo origen el comercio internacional, fundamentalmente entre Estados Unidos y los países latinoamericanos, era la razón para reducir las probabilidades de transmisión de enfermedades infecciosas $(1)^{3}$. Es decir, el mejora-

2 Pero fundamentalmente en África, donde las formas más severas de la enfermedad son principalmente ocasionadas por Plasmodium falcíparum y son las responsables de la mayoría de muertes por malaria en ese continente.

3 Los autores afirman que "Las reuniones periódicas especializadas en el tema sanitario convocaban a un buen número de los países de este continente y tenían como fin asegurar la cooperación eficaz entre ellos para mantener activo el comercio, con un mínimo riesgo de difusión de enfermedades, especialmente en el territorio de Estados Unidos". 
miento de las condiciones sanitarias de las poblaciones dependía de donde habitaran, si se trataba de lugares importantes para los mercados se mejoraban, de lo contrario quedaban por fuera. ¿¿Habrá cambiado mucho esta situación? Como suele suceder, la respuesta puede no ser una sola, dependiendo de la perspectiva. Diría que no, pero, si somos prácticos, qué nos importa la motivación si la consecuencia es la misma. Esta mejoría de las condiciones sanitarias no ha sido otra cosa que un efecto secundario, por fortuna favorable a quienes ocuparon esas zonas.

Ahora bien, ¿cómo puede justificarse no hacer algo cuando se sabe qué debe hacerse? La limitación de recursos financieros y humanos podría ser una respuesta. El rápido control del SARS en 2003(2) deja sin piso esa justificación o al menos hace que tambalee. La Organización Mundial de la Salud (OMS) lanzó rápidamente la alerta mundial y apoyó financieramente y con recursos técnicos y humanos la investigación de la epidemia hacia su control, y pudo lograrse de "manera oportuna y efectiva", en palabras del mismo organismo, pocas semanas después. Los sistemas de vigilancia epidemiológica de los países afectados funcionaron y se pudo hacer el seguimiento de la transmisión del virus en cada sitio que tocó. Esto simplemente sugiere que, si bien escasos, los recursos financieros están disponibles, al igual que los humanos. La epidemiología ha alcanzado un desarrollo tal en sus métodos que hoy los epidemiólogos en cualquier lugar del mundo están en condiciones de "detener" epidemias, aunque su causa o causas no estén plenamente establecidas. Como disciplina científica ha demostrado que no es imprescindible establecer las causas para ser efectivos en la prevención o el control de los problemas en salud pública, sean éstos permanentes o emergentes. Su abordaje del riesgo y los factores que lo incrementan o lo reducen resulta efectivo a la hora de controlar epidemias. Como se dijo, se dispone de las técnicas y de quienes están preparados para ponerlas en funcionamiento, lo que se requiere es que las enfermedades representen riesgos para la economía y que las pérdidas potenciales en el plano económico superen los costos de las estrategias de control, de lo contrario, no se justifica adelantarlas.

Esta es la perspectiva del presente ensayo. Dar una mirada a ciertas enfermedades de minorías que, dicen algunos, están huérfanas. Se trata, en un comienzo, de ubicar el problema y dar una ojeada a tópicos de interés en bioética, como la justicia y la no maleficen- cia, planteando que los problemas no están solamente por los lados de la tecnología, los recursos humanos o financieros, como pareciera plantearse desde ciertas perspectivas, así ellos jueguen un papel importante. El asunto también se relaciona con la sociedad que venimos construyendo, una para la cual hay vidas y muertes que importan, otras que no, al igual que hay enfermos y enfermedades que importan y otros no. Detrás de esto también hay asuntos de seguridad, no precisamente desde la perspectiva de salud, sino de la guerra y de la protección de los mercados. No se trata de establecer conclusiones; sí de continuar haciendo preguntas de interés en bioética.

\section{Las cuentas claras...}

El 87\% de los 2 trillones de dólares en gastos de atención en salud globalmente va al $16 \%$ de la población mundial y tan sólo un $10 \%$ de la carga global de enfermedad se lleva consigo el $90 \%$ del gasto global en investigación científica(3). Es decir, una minoría de enfermedades se gasta una mayoría de los dineros, tanto en materia de atención como de investigación en salud.

Según la Organización Panamericana de la Salud (OPS), a finales de los años 90 la mortalidad infantil por enfermedades transmisibles contribuyó con una pérdida de años de vida potencial ${ }^{4} 6,1$ veces más grande en países de bajo ingreso per cápita (menos de 3.000 dólares anuales) y alta brecha (razón de ingresos igual o superior a 13,75 entre el $20 \%$ de población que más recibe y el $20 \%$ que recibe menos), en comparación con aquellos que muestran alto ingreso y baja brecha(4). El mapa de las muertes infantiles se corresponde con el mapa de la pobreza y la exclusión. Sin embargo, la mortalidad infantil entre la llamada población afroamericana en los Estados Unidos es similar a la de países donde los ingresos son bajos y la brecha es alta, y ahí también hay mayores cifras de mortalidad materna o perinatal. He ahí otra realidad paradójica, el país más poderoso del planeta está mostrando cifras de salud pública, en ciertas comunidades en su interior, similares a las que

4 Los Años Perdidos de Vida Potencial (APVP) constituyen un indicador del peso que la mortalidad prematura ejerce en una población específica. En la actualidad, la carga de la enfermedad se mide por un indicador considerado más completo, los Años de Vida Saludable Perdidos, el cual tiene en cuenta tanto la mortalidad como la morbilidad. Sin embargo, los APVP siguen siendo útiles principalmente en el Tercer Mundo, donde la mortalidad temprana sigue siendo un problema de salud pública. 
por décadas vienen presentando los llamados países atrasados. La equidad que traería la globalización y el libre mercado quizá no sea tan universal y pareciera que tampoco ocupa todos los espacios, aun en los países desarrollados.

Adicionalmente, no sólo enfermedades infecciosas son las que muestran diferencias Norte-Sur en el planeta. Un artículo científico publicado a fines de 2004 afirmaba: "35 millones de personas morirán en 2005 por enfermedad cardiaca, accidente cerebrovascular, cáncer y otras enfermedades crónicas. Únicamente $20 \%$ de estas muertes ocurrirán en países de altos ingresos"(5). Entonces, las llamadas enfermedades crónicas, supuesto patrimonio de las sociedades avanzadas que ya habían superado la hegemonía de las infecciosas, terminan matando mucha más gente al Sur que al Norte. Algo similar sucede con la esperanza de vida: "...un recién nacido hoy en Japón, por ejemplo, puede esperar vivir 82 años en promedio, mientras es improbable que un recién nacido en Zimbabwe alcance la edad de 34 años"(2). Treinta y cuatro ańos es menos de la edad promedio alcanzada por los europeos en el medioevo. He aquí una triste realidad. El siglo XXI mostrando esperanzas de vida de los siglos catorce y quince, en un ambiente científico-tecnológico en el campo de la biomedicina sencillamente inimaginable para nuestros abuelos.

El asunto sin embargo no se queda en el terreno de la distribución desigual de las enfermedades, sean infecciosas o no. Según la OMS, la industria farmacéutica destina 13 veces más dinero para investigar en medicamentos contra las enfermedades cardiovasculares que contra las enfermedades tropicales (incluida la tuberculosis, usualmente asociada con el virus de inmunodeficiencia humana), aunque ambos grupos de patologías representen un mismo impacto global, alrededor de un $12 \%$ de la carga de enfermedad medida por AVISA (Años de Vida Saludable Ajustados por Discapacidad) (6). En ese sentido, la carga de enfermedades infecciosas respecto de las cardiovasculares en las sociedades avanzadas resulta pequeña y los principalmente afectados son minorías nativas o provenientes del llamado Tercer Mundo, que muy poca capacidad de pago o aseguramiento tienen. En cambio, el mercado de los medicamentos dirigidos al manejo de los problemas relacionados con el sobrepeso, la diabetes, la hipertensión arterial, el colesterol elevado, etc. es muy amplio y competido; por tanto, la investigación se ve no sólo necesaria sino apremiante.
Lo hasta aquí referido permite afirmar que la falta de equidad es parte del paisaje de la aldea global y también que la marcada diferencia en la carga de enfermedades a un lado del mundo no se corrige simplemente con una mejor disponibilidad o acceso a los medicamentos, o las medidas preventivas específicas con las cuales controlarlas. Los medicamentos como tales no son todo lo responsables que se piensa en materia de reducción de la carga de enfermedad por patologías transmisibles ni del incremento en la esperanza de vida. El mejoramiento en las condiciones de vida, el acceso a la educación, entre otros, son factores que quizás juegan un verdadero papel protagónico. Para Evans y colegas, “... los datos longitudinales del Reino Unido no muestran evidencia alguna de que la introducción del National Health Service haya reducido el gradiente de mortalidad", y agrega "...las medidas que resultaron decisivas fueron de salud pública y no de terapia médica" (7). Estos autores, al hablar de los cambios observados en el Reino Unido en cuanto a comportamiento de la tuberculosis se refiere, afirman: "Uno se sigue quedando con la interesante pregunta de por qué la gente expuesta a la 'causa' de la tuberculosis -el bacilo- en un siglo desarrolló la enfermedad y en el siguiente no". Líneas adelante finaliza diciendo que "lo fundamental del declive en la mortalidad por la mayoría de las enfermedades infecciosas antecedió en el tiempo a la terapia eficaz" (7:13).

\section{¿Dónde está el problema y a quién atañe?}

$\mathrm{Si}$ el asunto no es de dinero y tampoco de recursos humanos o tecnológicos, quizá el problema esté en otro lugar. Ese lugar, cualquiera que sea, atañe a la bioética por tener que ver con uno de sus principios fundamentales, la justicia, pues "...los países ricos ya no pueden ignorar por más tiempo las epidemias de diarrea que se cobran la vida de infinidad de niños de los países pobres, porque ya no podemos seguir sosteniendo que no se puede hacer nada desde el punto de vista médico" (8). Hay medicamentos, hay medidas efectivas de prevención y control de epidemias y se sabe que todo eso funciona.

Pero, por otro lado, aparte de la justicia, también parece estar relacionado con la seguridad de los países que han alcanzado unos estándares de vida nunca antes vistos y se sienten amenazados por aquellos que "no han sido capaces de lograrlos". La OMS lo refiere claramente: "Hoy día, tratar a otros de forma justa no 
sólo es un imperativo moral sino también un aspecto de una política de seguridad sensata"(9). Resulta, de cierta forma, paradójico que un principio ético como la justicia haya tenido que esperar la real o supuesta embestida del mal (expresado en el terrorismo) para encontrar un lugar entre las prioridades en el ámbito de la salud pública. Lo que no ha conseguido la justicia puede ser que lo logre la seguridad. Aunque no viajen en aeroplanos como ejecutivos, los refugiados y desplazados están llegando a todas partes y con ellos viajan sus virus, sus parásitos, sus hongos y sus bacterias. Se trata de bombas de tiempo, el que tarda el período de latencia o de incubación(10-12) de la enfermedad infecciosa que portan.

\section{¿Dónde están los excluidos? ¿̨Al Norte o al Sur?}

Ya no hay cortina de hierro, llevamos varios años sin muros a la vista que separen los "buenos" de los "malos" porque se acabaron esos "malos". El mundo entero ahora es Occidente aunque, inocente sería negarlo, sigue habiendo un Occidente al Sur y otro al Norte. Sólo que al interior del Occidente del Norte también está el Sur. Por tanto los muros, consideran los "buenos", van a seguir haciendo falta para contener a los "malos", aunque todos seamos occidentales, aunque el planeta entero sea Occidente por todas partes. Se trata de nuevos "malos" que portan otras costumbres y otras religiones, pero además otras enfermedades y, en consecuencia, ponen en riesgo a los "buenos".

Estos seres humanos provienen de lugares donde habita la mayoría de los desnutridos del mundo, la mayoría de los portadores del SIDA y de tuberculosis, la mayoría de los que sufren malaria, dengue o enfermedades hemorrágicas virales, la mayoría de los que padecen enfermedades parasitarias y se mueren de entidades como el sarampión o la tos ferina, evitables con vacunas. Todas esas enfermedades, excepto el SIDA, estaban ahí hacía tiempo. No se trata de enfermedades emergentes o nuevas, ni enfermedades reemergentes o que reaparecieran en esos lugares, simplemente han sido enfermedades que nunca se fueron y hoy siguen

5 Epidemiológicamente hablando, el período de latencia es aquel que tarda un agente infeccioso en ser capaz de transmitirse a otro ser humano una vez que infectó a una persona. Por su parte, el período de incubación es el tiempo que transcurre entre el momento de la infección con un agente infeccioso y la aparición de las primeras manifestaciones clínicas de la enfermedad en el individuo ya infectado. siendo tan frecuentes como en el pasado, así nos hayan convencido de que son enfermedades exóticas, rarezas, en fin, enfermedades de minorías. A pesar del calificativo, se trata de enfermedades mayoritarias (las primeras causas de muerte y hospitalización) en las poblaciones donde ocurren, poblaciones éstas donde se concentran casi todas las enfermedades infecciosas y no infecciosas del planeta.

Ni la inclusión o la exclusión forzosa de las culturas, ni la crueldad interna de algunos de sus propios líderes para impedir que miembros de unas culturas se mezclen con otras, ni la marginalización de los individuos que rompen con sus culturas originales(13) han logrado acabar por completo las identidades, que además no son estáticas ni lo han sido históricamente. Se sabe que las minorías pueden terminar siendo mayorías y el Banco Mundial es consciente de ello: la pobreza viene en aumento y se está convirtiendo en el obstáculo más difícil de salvar hacia el logro de aquello que empezó llamándose "Salud para todos en el año 2000", pero al poco tiempo, luego que solamente un país alcanzara las metas para esa fecha, pasó a ser "Salud para todos" y últimamente se le adicionó "en el siglo XXI", es decir, nos quedan casi 100 años para lograrla.

Si identidad implica reafirmación del ser en el marco de una cultura con prácticas compartidas y enraizadas -además de una visión del mundo y de la vida, a veces en contradicción y lucha ante cualquier tipo de dominación-y significa pertenencia y necesidad de un territorio donde vivir en concordancia con lo que se piensa y se quiere, entonces también implica autonomía para el ejercicio del ser y la construcción de una perspectiva de futuro(14). Estas identidades se van construyendo en la interacción cotidiana de los seres humanos, dentro de sociedades que, en no pocas ocasiones, las excluyen y por tanto deben luchar por sus derechos. Entonces, en el ejercicio de los derechos surgen identidades que desean ser reconocidas y aceptadas, esto es, culturas

6 La Primera Conferencia Internacional sobre Atención Primaria de Salud en Alma-Ata, Kazajistán, en 1978, convocó a 134 países y 67 organizaciones internacionales. La conferencia definió y otorgó reconocimiento internacional al concepto de "atención primaria de salud" como una estrategia para alcanzar la meta de Salud para Todos para el 2000. La grave desigualdad existente en el estado de salud de la población, especialmente entre los países en desarrollo y los desarrollados, así como dentro de cada país, es política, social y económicamente inaceptable y, por lo tanto, motivo de preocupación común para todos los países. Extractos de la página http://www.paho. org/english/dd/pin/alma-ata_declaration.htm, consultada el 30 de mayo de 2008 . 
dignas de consideración y respeto, que debieron ser tenidas en cuenta cada vez que algo -una política de salud, por ejemplo- pudiera afectarlas. El irrespeto por sus derechos es parte entonces de las razones para su origen y su consolidación. Pero, por otro lado, el irrespeto a sus derechos también los identifica y les refuerza en su identidad.

Si en tiempos de la inquisición se mataba brujas porque transgredían órdenes mayoritarios, hoy se hace lo mismo con identidades y culturas que puedan transgredir u obstaculizar el orden mundial. Puede ocurrir que no se maten o que no se destierren, pero se dejan morir, que termina siendo lo mismo.

Hay en los países desarrollados y del tercer mundo identidades que importan y otras que no. Realmente importa la cultura del consumismo, una identidad que nunca ha tenido que pelear por sus derechos porque la sociedad de mercado se los entregó todos, aun el de pisotear a otros.

\section{¿Del ahogado, el sombrero?}

$\mathrm{Al}$ menos empieza a verse clara la existencia de enfermedades que pueden afectar pequeńas comunidades susceptibles de llevarse a cualquier parte del mundo y ello abre la posibilidad de que se intente hacer algo por superarlas en su "lugar de origen". Ello obligó a la propia OMS a conformar equipos de expertos en algunas de tales patologías, con el fin de que se controlen localmente epidemias que en el pasado nunca se salían de sus áreas endémicas, pero hoy viajan en aeroplano a cualquier sitio. Esas enfermedades de minorías están poniendo en aprietos a las autoridades de salud pública del planeta entero y esto, no la justicia ni la beneficencia, está obligando a poner la mirada en esos guetos, aquellos lugares donde nacen, medio viven y mueren millones de otros seres humanos que parecieran hacer parte de aquello que últimamente han dado en llamar la "otredad".

Unas pocas palabras al respecto: que los seres humanos seamos diferentes entre nosotros, está claro; que buena parte del reconocimiento del otro esté en nuestro propio reconocimiento, quizás no tenga mayor discusión. Hay, sin embargo, cierto discurso alrededor de la "otredad", un discurso que acepta la injusticia como diferencia, un discurso que conforma una tendencia que se masifica y, por ello, empieza a lucir sospechosa. Esa preocupación por el otro se diluye en el otro animal, en el otro ambiente, en la otra planta y hace a un lado al otro ser humano. Hoy parece conmovernos más que se maten cientos o miles de focas o ballenas a un lado del mundo y muy poco que siga habiendo niños que cada mañana salen por los campos en busca de cucarachas para el almuerzo.

Que hayamos avanzado como especie por preocuparnos ahora por la vida en el planeta como un todo $-y$ también por su porción no viva que resulta fundamental para la vida - era un hecho extraordinario e impensable hace un tiempo, bajo la excluyente mirada antropocentrista. Pero algo anda mal si nos produce más dolor la muerte de las focas que las masacres o la guerra preventiva. Algo anda mal si nos conmueve el regreso de un tigre a su hábitat natural luego de varios años de prisión en un circo o el zoológico particular de un coleccionista o un mafioso, pero nada sintamos ante los miles de desplazados o de refugiados en el planeta. Poner énfasis en el ser humano no significa regresar al antropocentrismo, simplemente significa no permitir que se pierda en cierto discurso de la "otredad", uno que coloca al otro ser humano al mismo nivel que un perro, un gato o una mariposa. Somos mejores seres humanos cuando no permitimos que se experimente con otros animales causándoles dolor y sufrimiento, pero no lo somos cuando volteamos la mirada al conocer que algunas casas farmacéuticas adelantan experimentos con personas por el solo hecho de habitar aquellos lugares donde el discurso de los derechos humanos no ha hecho ningún efecto, por cuanto ningún interés hay en que haga efecto alguno $(15)^{7}$. Poner en el centro del otro al otro ser humano quizá también signifique que debemos cuidar todo lo no humano, porque hacer otra cosa es actuar con maleficencia y el daño que hagamos a la vida afecta todas sus formas, incluida la humana.

Michel Foucault afirma que: "Cada cultura define de una forma propia y particular el ámbito de los sufrimientos, de las anomalías, de las desviaciones, de las perturbaciones funcionales, de los trastornos de conducta que corresponden a la medicina”(16). La cultura del mercado ha definido los sufrimientos, las anomalías, las desviaciones y las perturbaciones funcionales de las que deberíamos ocuparnos y requieren de intervención en salud pública. Esta cultura ha dicho qué enfermedades son susceptibles de ser prevenidas,

7 En 2002, "investigadores en sus propias clínicas formularon eritromicina en "tabletas vaginales" como anticonceptivos en más de 790 mujeres pobres e iletradas en Bengala". 
diagnosticadas y tratadas; ha definido qué problemas de salud deben ser los prioritarios hacia su estudio y asignación de recursos para investigación; ha definido quiénes tienen derechos de propiedad intelectual en materia de tecnologías diagnósticas o formas de tratamiento de enfermedades conocidas hace tiempo o recientemente "inventadas". Bajo esa cultura, como en el pasado bajo otras, aparecen enfermos y enfermedades que importan. Hoy son parte de los enfermos y las enfermedades que importan aquellos y aquellas que pueden poner en riesgo el libre intercambio global de mercancías y aquellos y aquellas cuyos tratamientos, por costosos que sean, son asumidos y cubiertos sin problema por las sociedades y las fracciones de población más poderosas económicamente.

Hace unos meses se publicó en The Lancet una serie de artículos acerca del comercio y la salud. En uno de ellos se afirma: "Mucho antes de desarrollada la teoría del germen, los gobiernos adoptaron medidas para prevenir la importación de enfermedades asociadas con el comercio, tales como la plaga y el cólera" (17). Es decir, el comercio y la salud han convergido hace tiempo, el problema es que, siendo como parece, tanto el comercio como la salud asuntos vinculados de alguna manera con la justicia, deberían abordarse políticamente, por cuanto los asuntos de justicia en estas dos esferas también atañen a la política, así nos hayan hecho creer que se trata de asuntos meramente técnicos, esto es, que deben ser tratados por expertos. La política sería entonces la encargada de buscar conciliar el comercio y la salud, con el fin de que la balanza no opere solamente a favor del primero.

Pudiera decirse que hay implicaciones directas de la llamada globalización de la economía sobre la salud, como la probabilidad de reintroducción de agentes infecciosos en territorios ya libres de ellos, tema abordado la última década del siglo XX por OMS al plantear la existencia de enfermedades infecciosas emergentes y reemergentes, pero hay otras que no pueden asumirse como simples efectos colaterales o indirectos, pues afectan negativamente las condiciones de vida de los seres humanos, sobre todo en el denominado Tercer Mundo.

El mercado global no solamente favorece la diseminación de patógenos, sean o no infecciosos, también ha ocasionado daño a los llamados "determinantes sociales de la salud" en su sentido más amplio, uno de ellos el evidente deterioro en las condiciones de trabajo, por dar un ejemplo. Pero también el comercio tiene injerencia directa en los sistemas de atención en salud de los países mediante las agencias privadas de seguros, algunas de ellas verdaderas multinacionales del aseguramiento en este campo. La industria farmacéutica, sus patentes y derechos de propiedad intelectual constituyen otro factor relevante en la relación comercio-salud que ha supeditado esta última a los intereses del primero.

\section{Comentario adicional}

"Da vigor a mi cuerpo y a mi espíritu, a fin de que esté siempre dispuesto a ayudar al pobre y al rico, al malo y al bueno, al enemigo igual que al amigo. Haz que en el que sufre yo no vea más que al hombre" (Maimónides)(18).

Si el ámbito de lo patológico no es el mismo en todos los lugares y los tiempos, ¿por qué hemos aceptado ejercer una medicina que no atiende nuestros más importantes problemas de salud? Hablamos de sociedades pluriétnicas y multiculturales, pero nuestra medicina no apunta a dar respuesta al panorama de enfermedades que aquejan a etnias y culturas que supuesta o realmente no son mayoritarias. No parece razonable o justo que la medicina avance a pasos agigantados pero deje una estela de enfermedades sin resolver a pesar de semejantes avances. ¿Es que no importan esas enfermedades o es que no importan las etnias, las culturas o las fracciones de población que las sufren? Lo que parece estar sucediendo es que todas las enfermedades importan siempre y cuando afecten a personas que importen a esta gran cultura universal del mercado. Si "en último término, la enfermedad es, en una época determinada y en una sociedad concreta, aquello que se encuentra teórica y prácticamente medicalizado"(16), quizá sea necesario avanzar en la búsqueda de otra medicina, porque ésta -al menos bajo la hegemonía de la cultura universal del consumismo- no pudo dar respuesta a los más serios problemas que tiene enfrente, así sean ellos los medicalizados.

Hay otras miradas de la enfermedad, como otras miradas de lo justo, de lo malo, de lo bello. Si aceptamos que vivimos en sociedades plurales, multiculturales o multiétnicas, deberíamos aceptar que todos contamos, que todos somos importantes aunque estemos o nos sintamos afectados de enfermedades que para otras culturas no existen o resultan irrelevantes. Seguimos estando equivocados si sólo atendemos enfermedades de minorías, enfermedades del occidente del sur, cuando hay riesgo de que nos toquen al norte, de que interfieran 
nuestro comercio, de que dañen nuestros negocios. Es injusto, es malintencionado y por tanto maleficente, que disponiendo como disponemos hoy de los más grandes avances biomédicos en la historia de la humanidad, esas enfermedades nada o muy poco importen, y seguimos estando muy equivocados si esos sujetos, esas culturas, esas identidades sólo son tenidas en cuenta por razones de seguridad, es decir, de guerra.

Reza un bello proverbio africano: "No heredamos la tierra de nuestros padres, sino que la tomamos prestada de nuestros hijos" (19). África ha visto arrasar sus tierras, estigmatizar, cuando no exterminar, sus innumerables identidades culturales y sembrar de tumbas sus campos. A los africanos, como a ciertos americanos al Sur, se les está condenando a no poder devolver la tierra que sus hijos les prestaron. Aparte de enfermedades hace rato susceptibles de control y prevención, hay otro problema de salud pública que urge atención en estos lugares, la violencia. Acá se mata y se deja morir. Hay poderosos de diferentes tipos, unos por su inverosímil riqueza, otros por las armas con que cuentan sus ejércitos privados, otros por la corrupción que invade todos los ámbitos de la sociedad, que matan o dejan morir, finalmente lo mismo, aunque dejar morir suene simplemente a muerte natural.

En África como en América se trata de culturas que no quieren ser arrancadas de los territorios donde se fundan, pues no se trata de ciudadanos del mundo (el del mercado), sino de seres humanos que ven en esa porción de tierra mucho más que fuentes de recursos naturales, zonas de megaproyectos, parques ecoturísticos, lugares de práctica de deportes extremos, espacios para la agricultura y la ganadería a escala industrial o biodiversidad para ser patentada.
Hubo, y hay aún, personas y culturas que madrugaron a la globalización para no dejar que arrase todo bajo la égida de su dios mercado. Ellas por ejemplo no han permitido que las poderosas multinacionales de las drogas impongan los precios de los medicamentos a los pueblos que enferman y mueren por no poder acceder a los fármacos, y han dicho cosas parecidas a la siguiente: con nuestra tecnología, quizá menos avanzada que la suya, podemos producirlos a la cuarta parte del valor que ustedes nos los venden. En consecuencia, o llegamos a un acuerdo menos oneroso para nuestro pueblo o simplemente no les volveremos a comprar. Eso al menos pasó en Sudáfrica y Brasil hace poco tiempo. Los argumentos de sus presidentes terminaron ganando apoyos, subjetividades en el mundo enter ${ }^{8} \mathrm{y}$, para no aumentar su desprestigio, las multinacionales cedieron.

El mercado no tiene leyes, son los mercaderes quienes las imponen. Las casas farmacéuticas no son diferentes de otras industrias, sus productos están fundamentalmente para la venta, no para la salud ni la vida. Para estas últimas están las sociedades y sus gobiernos. El intercambio entonces se puede negociar de manera que no se llenen las arcas de los mercaderes a costa del empobrecimiento, la enfermedad y la muerte de mayorías o minorías en muchos pueblos.

Estas son lecciones que muestran que sí es posible incluir, que sí es posible ser justos y hacer el bien, precisamente por respetar la autonomía y no tener que seguir haciendo daño al excluir individuos, subpoblaciones o poblaciones que al mercado no importan, pero que deben importar a los seres humanos. Puede tratarse de simples golondrinas que, sin embargo, están haciendo verano.

8 El Vaticano mismo hizo llamados a la industria farmacéutica con el fin de que bajara los precios de los medicamentos antiretrovirales a comienzo de 2004, y la noticia acerca del "genocidio" que las casas farmacéuticas estaban cometiendo dio la vuelta al mundo a través de los diferentes medios de comunicación. 


\section{Referencias}

1. OPS/OMS. La Organización Panamericana de la Salud y el Estado colombiano: cien años de historia 1902-2002. OPS; 2002: 31 .

2. Prah Ruger J. Health and Social Justice. The Lancet 2004; 364(9439): 1075-1080.

3. Sinnger P, Benatar S. Beyond Helsinki: a vision for global health ethics. BMJ 2001; 322: 747-748.

4. OPS/OMS. La salud en las Américas. Volumen 1; Edición 2002: 19.

5. Strong K, Mathers C, Leeder S, Beaglehole R. Preventing chronic diseases: how many lives can we save? Lancet 2005 Oct 29-Nov 4;366(9496):1578-1582.

6. Keyeux G. Bioética y salud pública: la genómica en la salud del futuro. Cuadernos del doctorado, Universidad Nacional de Colombia, 2005; 2. Ética, salud y vida.

7. Evans RG, Barer ML, Marmor TR. ¿Por qué alguna gente está sana y otra no? Madrid: Díaz de Santos; 1996: 11.

8. Matt R. Genoma. Madrid: Editorial Punto de Lectura; 2001: 465.

9. OMS. Informe sobre la salud en el mundo 2003. Ginebra: OMS; 2003: 8.

10. Giesecke J. Modern Infectious Disease Epidemiolgy. Hodder Arnold, Second Edition; 2002.

11. Rothman K, Greenland S. Modern Epidemiology. Lippincott-Raven; 1998.

12. Rivas F. Epidemiologia: Fundamentos. Facultad de Medicina, Universidad Nacional de Colombia; 2008.

13. Guerra MJ. Diferencias culturales y derechos humanos: una cuestión urgente para la bioética global. En: García GómezHeras JM, Velayos Castelo C. (coords.) Bioética. Perspectivas emergentes y nuevos problemas. Madrid: Tecnos; 2005.

14. Escobar A. Más allá de Tercer Mundo. Globalización y diferencia. Colombia: Instituto Colombiano de Antropología e Historia, Universidad del Cauca; 2005: 61.

15. Nundy S, Gulhati ChM. A New Colonialism? - Conducting Clinical Trials in India. N Engl J Med 2005; 352: 16331636.

16. Foucault M. La vida de los hombres infames. Buenos Aires: Altamira; 1996: 21.

17. Fidler D, Drager N, Kelley L. Managing the pursuit of health and wealth: the key challenges. The Lancet 2009; 373: 325 .

18. Massué JP. Prefacio. En: La saludy los derechos humanos. Aspectos éticos y morales. Washington DC: Consejo de Europa, Organización Panamericana de la Salud. Publicación Científica No 574; 1999: 5.

19. Renaud M. El futuro: ¿Hygeia versus Panakeia?. En: Evans RG, Barer ML, Marmor TR. ¿Por qué alguna gente está sana y otra no? Madrid: Díaz de Santos; 1996: 347.

Recibido: 3 de diciembre de 2009

Aceptado: 22 de marzo de 2010 